\title{
Analisis Faktor Penyebab Keterlambatan Penyerahan Klaim BPJS di RS Panti Nugroho
}

\author{
Lenty Wahyu Noviatri ${ }^{1}$, Sugeng ${ }^{2}$ \\ Program Studi DIII Rekam Medis Sekolah Vokasi UGM ${ }^{1}$, RSUP dr Sardjito ${ }^{2}$ \\ lenty.w.n@gmail.com ${ }^{1}$, sugeng.icm@gmail.com²
}

\begin{abstract}
ABSTRAK
Latar Belakang: Keterlambatan penyerahan berkas klaim pasien rawat inap disebabkan karena berkas rekam medis yang kembali dari bangsal rawat inap tidak lengkap sehingga harus dikembalikan untuk dilengkapi oleh dokter penanggung jawab. Sedangkan keterlambatan klaim BPJS untuk pasien rawat jalan disebabkan karena persyaratan dan ketentuan administrasi klaim yang selalu berubah-ubah membuat banyak berkas klaim yang dikembalikan oleh verifikator sehingga prosesnya menjadi terhambat. Apabila terjadi keterlambatan penyerahan berkas klaim, maka berkas klaim tersebut akan di-pending penyerahanya dan akan diikutsertakan pada proses klaim bulan selanjutnya.

Tujuan: mengetahui penyebab terjadinya keterlambatan penyerahan berkas klaim BPJS kepada verifikator independen di Rumah Sakit Panti Nugroho

Metode: diskriptif dengan pendekatan kualitatif dan rancangan penelitian studi kasus. Subyek yang menjadi penelitian ini adalah petugas yang terlibat secara langsung dalam proses klaim. Obyek yang menjadi penelitian ini adalah pengajuan berkas klaim pasien rawat jalan dan rawat inap dengan cara bayar BPJS.

Hasil: Proses pelaksanaan klaim BPJS di Rumah Sakit Panti Nugroho sudah lancar tetapi masih terdapat berkas klaim yang diserahkan terlambat. Faktor penyebab keterlambatan klaim berasal dari faktor man adalah petugas verifikator kelengkapan awal, dokter, dan petugas pengodean. Faktor machine adalah karena SIMRS belum terintegrasi dengan INA-CBG. Methode adalah karena implementasi SPO yang belum lancar. Faktor materials karena persyaratan yang tidak sesuai. Upaya yang telah dilakukan oleh petugas pada faktor man adalah melakukan sosialisasi pada pasien, berkomunikasi dengan dokter, mengupayakan perekrutan. Machine adalah melakukan back-up data. Faktor methode adalah membentuk tim BPJS di Rumah sakit Panti Nugroho.
\end{abstract}

Kata Kunci: penyebab keterlambatan, klaim BPJS

\begin{abstract}
Background: The late of inpatient BPJS claim caused by incomplete medical record so the medical record should returned back until responsible doctor completing that medical record. Meanwhile the late of outpatient BPJS claim is caused by BPJS request that always changing and resulting BPJS claim should returned by BPJS verificator. If the BPJS claims are late, they will give the claim process in next month. Objective: to knowing BPJS claim process, to knowing the late causes of BPJS claim process, to knowing how employment resolve the late causes of BPJS claim process

Methods: kind of this research is descriptive study with qualitative approach using case study design. The subject is all employment who belong to BPJS claim process. The object is inpatient and outpatient BPJS claim document.

Results: the process of BPJS claim in Rumah Sakit Panti Nugroho is going well but still found BPJS claim which given late. The late causes of BPJS claim process is coming from early complete verifier, phsycian, and coder. The machine factor is BPJS server is SIMRS and INA-CBG are not integrated yet. The method factor is there is trouble in SPO implementation. The materials factor is the applying record is not complete. Employment resolve that late causes by man factor is give patient an information, communicating with doctor, and try to recruiting employment. Machine factor is do back-up the patient data. Method is forming BPJS team in Rumah Sakit Panti Nugroho.
\end{abstract}

Key words: Late causes, BPJS claim 


\section{PENDAHULUAN}

Sejak 1 Januari 2014 pemerintah secara resmi memberlakukan program Jaminan Kesehatan Nasional (JKN). Demikian pula dengan Badan Penyelenggaraan Jaminan Sosial (BPJS) juga mulai diberlakukan untuk menyelenggarakan program tersebut. Tujuan diberlakukan program JKN ini adalah untuk memenuhi kebutuhan kesehatan masyarakat yang layak dan diberikan kepada setiap orang yang terdaftar dan telah membayar premi atau preminya dibayarkan oleh pemerintah.

Berdasarkan studi pendahuluan yang dilakukan oleh peneliti di Rumah Sakit Panti Nugroho pada bulan Januari 2016, diketahui bahwa berkas klaim pasien BPJS diserahkan kepada verifikator BPJS pada tanggal 15 bulan berikutnya. Kemudian hasil verifikasi diserahkan kepada BPJS pada tanggal 17. Apabila terjadi keterlambatan penyerahan berkas klaim, maka berkas klaim tersebut akan dipending dan akan diikutsertakan pada proses klaim bulan selanjutnya. Hal ini akan berakibat pada menurunya jumlah hasil klaim yang didapat oleh fasilitas kesehatan pada bulan tersebut.

Keterlambatan penyerahan berkas klaim pasien rawat inap disebabkan karena berkas rekam medis yang kembali dari bangsal rawat inap tidak lengkap sehingga harus dikembalikan untuk dilengkapi oleh dokter yang bertanggung jawab. Sedangkan keterlambatan klaim BPJS untuk pasien rawat jalan disebabkan karena persyaratan dan ketentuan administrasi klaim yang selalu berubahubah membuat banyak berkas klaim yang dikembalikan oleh verifikator sehingga prosesnya menjadi terhambat.

Berdasarkan hasil wawancara dengan kepala rekam medis dan petugas rekam medis di Rumah Sakit Panti Nugroho, diketahui bahwa pelaksanaan klaim BPJS dalam hal penyerahan berkas klaim pasien kepada verifikator BPJS masih mengalami keterlambatan sehingga harus di-pending dan masih ada berkas klaim BPJS pasien yang dikembalikan untuk diperbaiki. Oleh sebab itu, peneliti tertarik untuk mengangkat topik tugas akhir evaluasi faktor penyebab keterlambatan penyerahan berkas klaim BPJS di Rumah Sakit Panti Nugroho.

\section{METODE}

Penelitian yang akan dilakukan adalah penelitian deskriptif dengan pendekatan kualitatif dan jenis penelitian studi kasus. Subjek dalam penelitian ini adalah petugas yang terlibat secara langsung dalam proses klaim BPJS yaitu sebanyak delapan petugas. Objek yang diteliti adalah berkas klaim pasien rawat jalan dan rawat inap dengan cara bayar BPJS.

Teknik yang digunakan dalam pengambilan data dalam penelitian ini adalah wawancara, observasi, dan studi dokumen. Langkah-langkah analisis adalah reduksi data, penyajian data, dan verifikasi.

\section{HASIL DAN PEMBAHASAN}

1. Pasien datang kerumah sakit dengan membawa persyaratan yang dibutuhkan lalu diserahkan kepada petugas verifikator kelengkapan awal. Jika telah lengkap, petugas akan mencetak surat eligibilitas. Petugas kassa mencetak karcis piutang. Lalu pasien dapat diperikasa oleh dokter. Dokter memutuskan apakah pasien bisa pulang atau harus mendapatkan rawat inap. Lalu pasien akan diarahkan ke bagian farmasi untuk mendapatkan obat. Petugas farmasi menyerahkan daftar obat yang digunakan pasien kepada petugas kassa. petugas kasa mengolahnya sehingga menjadi nota piutang. Lalu diserahkan kepada pentugas koding untuk digrouping. Dan menghasilkan file txt. File txt diserahkan kepada verifikator BPJS. Proses pelaksanaan klaim BPJS di Rumah Sakit Panti Nugroho sudah sesuai dengan Petunjuk Teknis Verifikasi Klaim BPJS tahun 2014 namun masih terdapat berkas yang terlambat.

2. Penyebab Keterlambatan Penyerahan Klaim pada Pelaksanaan Klaim BPJS di Rumah Sakit Panti Nugroho. Diurakan berdasarkan 5 unsur manajemen menurut Hasibuan (2008):

a. Man

Menurut Hasibuan (2008), faktor man merujuk pada sumber daya 
manusia yang dimiliki oleh organisasi. Faktor man yang menyebabkan keterlambatan dalam pelaksanaan klaim BPJS ditemui pada petugas verifikator kelengkapan awal yang tidak teliti dalam mengecek persyaratan pasien, dokter tidak lengkap mengisi resume, dan petugas pengodean yang melakukan kegiatan lain.

Pasien belum lengkap tapi pasien sudah terlanjur diperiksa atau pasien yang berobat dengan dokter spesialis padahal sudah dijadwalkan datang dalam waktu satu bulan tetapi datang dalam waktu satu minggu atau karena persyaratanya belum lengkap tapi pasien sudah terlanjur diperiksa. Kalau seperti itu, jadi tidak bisa di klaim-kan. Karna petugas terbatas maka petugas pengodean juga melakukan kegiatan lain

Triangulasi Sumber

b. Machines yang digunakan petugas terkendala pada server dari BPJS yang sering down sehingga petugas tidak dapat mengecek keanggotaan pasien dan bridging system terbatas pada aplikasi SEP saja.

Bridging hanya pada SEP saja itu saja masih terkendala server yang server yang masih error, untuk yang SIMRS belum karena masih rawan terputus jadi masih manual

Triangulasi Sumber

c. Methode, di RS Panti Nugroho sudah terdapat SOP namun masih terdapat kendala pada pengimplementasiannya.

Untuk implementasi SPO sudah baik tapi masih terhambat pada pegembalian berkas rekam medis dan mengenai surat rujukan yang tidak sesuai dengan jadwal kunjungan.

Triangulasi Sumber
3. Upaya yang dilakukan petugas untuk mengatasi keterlambatan penyerahan klaim dalam pelaksanaan klaim BPJS di Rumah Sakit Panti Nugroho:

a. Upaya yang dilakukan petugas dalam mengatasi Penyebab Keterlambatan dari faktor man adalah memberikan informasi kepada pasien agar kedepannya pasien membawa persyaratan dengan lengkap. Petugas pengodean berkomunikasi dengan dokter agar dokter segera melengkapi resume pasien. petugas rekam medis juga mengupayakan diadakan perekrutan tenaga rekam medis.

Jika ada lembar yang belum lengkap, jadinya tidak layak karena tidak memungkinkan apabila kita harus melakukan konfirmasi kepada pasien dan memanggil pasien yang sudah pulang dari rumah sakit. Itu akan memakan waktu yang semakin banyak. Jadi dianggap tidak layak.

Triangulasi Sumber

b. Upaya dalam mengatai Penyebab Keterlambatan dalam faktor machine adalah petugas melakukan back-up data secara rutin dan berkomunikasi dengan pihak BPJS. hal ini sesuai dengan peraturan mentri kesehatan nomor 27 tahun 2013 tentang petunjuk teknis sistem INA-CBG's.

Jika server down, kita ya cuma bisa nunggu karena itu kan yang bermasalah dari pusat. Tapi kita juga berkoordinasi dengan pusat, kami juga melakukan kontak dengan bagian IT untuk minta saran. Jika masih belum bisa kita melakukannya dengan manual. Kami sudah mulai melakukan back-up data secara rutin setiap satu bulan sekali untuk mencegah jika tiba-tiba program error.

Triangulasi Sumber 
c. Petugas membentuk tim BPJS merupakan upaya yang dilakukan petugas dalam mengatasi Penyebab Keterlambatan pada faktor methode yang terdiri dari penanggung jawab BPJS, koder, dan pihak manajemen untuk melakukan sosialisasi dan evaluasi terkait peraturan dari pihak BPJS. Hal ini sesuai dengan Peraturan Mentri Kesehatan 27 tahun 2014 tentang Petunjuk Teknis Sistem INA-CBG's yaitu membentuk tim case mix / tim INACBG's rumah sakit akan menjadi penggerak membantu melakukan sosialisasi, monitoring, dan evaluasi implementasi INA-CBG's di rumah sakit.

Ada pertemuan rutin membahas masalah yang ada setiap tiga bulan dengan bagian manajemen, keuangan, dan koder. membahas mengenai temuan-temuan kasus yang terjadi selama proses seperti peningkatan jumlah kunjungan bagaimana bila terjadi penumpukan lalu jika ada dokumen pasien yang tidak lengkap atau surat rujuka yang tidak sesuai tanggal. jadi evaluasinya lebih berfokuspada pelayanan pasien.

Triangulasi Sumber

\section{PENUTUP}

A. Kesimpulan

1. Proses pelaksanaan klaim BPJS di Rumah Sakit Panti Nugroho sudah sesuai dengan Petunjuk Teknis Verifikasi Klaim BPJS tahun 2014. Tetapi dalam pelaksanaannya masih terdapat resume medis yang tidak terisi atau terlambat pengembaliannya sehingga memperlambat proses pengajuan klaim BPJS karena harus menunggu dokter mengisi terlebih dahulu.

2. Penyebab Keterlambatan dalam Pelaksanaan Klaim BPJS di Rumah Sakit Panti Nugroho berasal.

a. Penyebab Keterlambatan yang berasal dari faktor man adalah petugas verifikator kelengkapan awal, dokter, dan petugas pengodean.

b. Penyebab Keterlambatan yang berasal dari faktor machine adalah server dari BPJS sering down dan bridging system yang masih terbatas.

c. Penyebab Keterlambatan yang berasal dari faktor method adalah pengimplementasian SOP yang belum lancer.

3. Upaya yang dilakukan oleh petugas dalam mengatasi Penyebab Keterlambatan dalam proses kalim adalah:

a. Upaya yang dilakukan untuk mengatasi Penyebab Keterlambatan pada faktor man adalah petugas memberikan informasi kepada pasien, petugas pengodean aktif berkomunikasi dan melakukan konfirmasi dengan dokter, petugas rekam medis mengupayakan untuk penambahan pegawai.

b. Upaya yang dilakukan untuk mengatasi penyebab keterlambatan pada faktor machine adalah petugas berkomunikasi dengan pihak BPJS dan melakukan back-up data secara rutin.

c. Upaya yang dilakukan untuk mengatasi Penyebab Keterlambatan pada faktor method adalah pihak rumah sakit membentuk tim BPJS yang bertugas melakukan sosialisasi dan evaluasi.

B. Saran

1. Sebaiknya petugas verifikator kelengkapan awal lebih teliti dalam melakukan pengecekan terhadap persyaratan klaim yang dibawa oleh pasien sehingga tidak ada berkas dari pasien yang tidak lengkap atau tidak sesuai.

2. Sebaiknya Kepala Sub Seksi Rekam Medis melakukan perhitungan ulang mengenai kebutuhan tenaga kerja untuk mengetahui apakah sub seksi rekam medis membutuhkan penambahan pegawai baru atau 
tidak. Sehingga rencana penambahan pegawai tidak hanya didasarkan pada subjektivitas petugas saja.

3. Sebaiknya dokter mengisi berkas rekam medis secara lengkap mengingat kebanyakan dokter di Rumah Sakit Panti Nugroho adalah dokter tamu dan tidak bisa stand by di rumah sakit sehingga petugas rekam medis tidak perlu mengembalikan berkas rekam medis pasien kepada dokter penanggung jawab pasien.

4. Sebaiknya tim IT bersama dengan Kepala Sub Seksi Rekam Medis mengembangkan bridging system antara SIMRS dan INA-CBG di Rumah Sakit Panti Nugroho agar menambah kemudahan dan efisiensi dalam penginputan data klaim pasien.

\section{DAFTAR PUSTAKA}

Hasibuan, M. (2008). Manajemen Sumber Daya Manusia. Jakarta: Bumi Aksara. Peraturan Mentri Kesehatan nomor 27 tahun 2014 tentang Petunjuk Teknis Sistem Ina-CBG's. [internet]. http://www.depkes.go.id. Diakses pada tanggal 19 Mei 2016.

Petunjuk Teknis Verifikasi Klaim BPJS Kesehatan Tahun 2014. [internet]. http://www.bpjs-kesehatan.go.id. Diakses pada tanggal 19 Desember 2015 